\title{
Risk assessment of debris flow based on group decision making - A case study of Luanchuan County, Henan Province, China
}

\author{
Pengyu Chen ${ }^{1, \mathrm{a}}$ and Ying Kong ${ }^{2}$ \\ ${ }^{l}$ School of Geography \& Resource Science, Neijiang Normal University, 641100 Neijiang, China \\ ${ }^{2}$ Faculty of Engineering, China University of Geosciences, 430074 Wuhan, China
}

\begin{abstract}
Luanchuan County, located in the mountains of Western Henan Province, is characterized by poor geological environment and abundant material sources and rainfalls. Debris flows have occurred many times in this county, and in some gully debris flows exhibit a large scale, requiring risk assessment. In the multi-factor comprehensive assessment methods for debris flow risk, it is really important to determine the weight of each factor since this affects the reliability of the assessment results. Given that the subjective weighting method can accurately reflect the importance of each factor, in order to improve the reliability of subjective weighting, the group decision making method is used to determine the weight of each factor. Group decision making is realized using the analytic hierarchy process and the data fusion algorithm. In this method, the expert combination weight is determined; on this basis, a model for comprehensive assessment of debris flow risk is established by the linear weighted sum method, and risk assessment is performed for gullies with medium to large-scale debris flows in the study area. The assessment results show that all debris flow gullies face minor to moderate risks. For gullies with high risk degree, it is suggested to timely clear material sources in channels and construct or reinforce retaining dams in order to prevent reoccurrence of debris flows.
\end{abstract}

\section{Introduction}

Luanchuan County, located in the mountains of Western Henan Province, is characterized by complicated topography, including crisscrossed mountains, precipitous landform, high gully slope and developed unstable slopes. Rock formations within the area are complex and diverse, strongly weathered with welldeveloped joints and thick loose slope wash. In the area, mining and other human engineering activities are intense, and rainfall is heavy and concentrated. All these factors have led to poor quality of geological environment and development of geological hazards represented by debris flows in Luanchuan County [1-2]. More than 30 debris flow hazards have been identified within the county and large-scale disastrous debris flows also break out intermittently, which seriously threatens the personal and property safety of local residents and adversely affects local economic development. Therefore, it seems quite necessary to assess the debris flow risk in the study area, and such evaluation will have great significance in prevention and reduction of debris flow hazards.

The debris flow risk refers to the probability that human beings and everything in their environment are harmed by debris flows. Theoretically, the debris flow risk can be defined as the definite integral of debris flow scale - frequency curve [3]. Since it is difficult to obtain the accurate values of debris flow scale and frequency, most existing methods involve multi-factor comprehensive assessment, such as linear weighted sum method, principal component analysis method, and matter-element extension theory [4-7]. Since each assessment factor contributes to the debris flow risk differently, it is extremely important to determine the weight of each factor in multi-factor comprehensive assessment methods as this concerns the reliability of the assessment results. Commonly, subjective, objective and combination weighting methods can be used for weight determination. Different methods rely on different computing ideas, thus leading to difference in the significance of weight. The objective weighting method, which determines the weight of each factor based on sample data, is often dependent on the fluctuation of data and varies with sample data [6]. The subjective weighting method determines the weight of each factor based on the decision maker (expert)'s subjective judgment of the importance of the factor, which can, to some extent, reflect the relationship between the debris flow risk and the factor [6], but is dependent on the expert's subjective will and experience level. Since the subjective and objective weighting methods use different computing ideas, significant difference often exists in the weight of factor respectively determined. Although the combination of these two methods can reconcile the difference between them to some extent, the significance of combination weight is no longer clear.

a Corresponding author: cpy_nj@163.com 
Since the subjective weighting method can directly reflect the degree of influence that each factor has on debris flows, this method is recommended in this paper. Given that the weighting result is affected by the expert's subjective will and experience level, it is suggested to use the group decision making method [8] which comprehensively considers judgment information of several experts to improve the reliability of subjective weighting. As a matter of fact, the group decision making method can also be regarded as a combination weighting method. Different from the subjective and objective combination weighting method, the group decision making method combines the judgment results from each expert. In comparison with decision making made by a single expert, this method improves the reliability, provides clear significance of combination weight, and can accurately reflect the importance of each factor. Therefore, the group decision making method is used in this study to determine the weight of each factor. On this basis, a model for comprehensive assessment of debris flow risk is established by the linear weighted sum method, and risk assessment is performed for gullies with medium to large-scale debris flows in the study area.

\section{Historical outbreaks of debris flows}

The county has a long history of mining. Some areas have been seriously reclaimed by human, mainly including deforestation, slag heaps, tillage on steep slopes, occupation of river courses, etc.; these have resulted in deterioration of the environment. Besides, the granite widely distributed within the county is intensely weathered along fissures, forming a thick weathered layer, and Quaternary slope wash is locally distributed. Since 1960s, the iron and steel making movement and other reasons have resulted in significant reduction in forest area, serious soil erosion, and frequent occurrence of debris flows; currently large amounts of debris flow deposits exit in channels. All these factors have provided abundant material sources for the formation of debris flows. In addition, Luanchuan County has good rainfall conditions, thus it has become one of the counties where geological hazards take place frequently in Henan Province.

As a result of such geological environment and rainfall condition, flood and debris flow hazards have occurred many times in the history of Luanchuan County. According to the Records of Civil Affairs of the county and the results of investigation, large-scale disastrous debris flows took place six times in total from 1953, approximately once every ten years on average. This suggests a low frequency of large-scale debris flows within the county. Due to the difference in rainfall condition, landforms, vegetation, solid matter supply sources and other factors, debris flows within the county are characterized by regional group occurrence although they commonly are not groupoccurring debris flows. Table 1 shows major regionally group-occurring debris flow hazards taking place in Luanchuan County in recent years. The severest debris flow hazard took place on July 24, 2010, on which day the rainfall in Luanchuan County reached $155.8 \mathrm{~mm}$, refreshing the historical record (128.8mm in 1961).

Table 1. Regionally group-occurring debris flow hazards taking place in Luanchuan County in recent years.

\begin{tabular}{|c|c|}
\hline Date & Description \\
\hline July 27, & $\begin{array}{c}\text { From zero to three o'clock, the maximum rainfall } \\
\text { per hour was nearly 100mm. Debris flows were } \\
\text { induced at Qigu Gully of Shimiao Town, Nan } \\
\text { Gully of Taowan Town and other locations, } \\
\text { carrying away 6 persons and resulting in over } \\
\text { RMB 10 million of property damage. }\end{array}$ \\
\hline July 29, & $\begin{array}{c}\text { In late July 2007, heavy rain to storm fell } \\
\text { frequently in the mountains of Western Henan } \\
\text { Province, leading to debris flow, landslide and } \\
\text { other geological hazards in many places. Debris } \\
\text { flows broke out in several areas of Jiaohe Town } \\
\text { and Taowan Town. }\end{array}$ \\
\hline July 24, \\
2010 & $\begin{array}{c}\text { A heavy rainstorm led to totally 29 debris flow } \\
\text { events in 14 Towns within Luanchuan County; } 68 \\
\text { people died, and 21 disappeared; buildings of some } \\
\text { schools and public health centers got damaged and } \\
\text { local road traffic interrupted; the direct economic } \\
\text { loss amounted to nearly RMB 1.98 billion. }\end{array}$ \\
\hline
\end{tabular}

\section{Group decision making model for assessment of debris flow risk}

\subsection{Assessment indicator system and classification criteria}

Currently, the debris flow risk is judged mostly by multi-factor comprehensive assessment. Since the debris flow risk can be interpreted as the definite integral of debris flow scale - frequency curve [3], the debris flow scale $M$ and the frequency of occurrence $F$ are the primary factors for risk assessment of debris flow and others are all secondary factors. The secondary factors should have a marked impact on the scale and frequency of debris flows. In this study, the secondary factors for risk assessment of debris flow were chosen from the rainfall condition and the geological background. Given that assessment factors should be scientific, representative, comprehensive and easily accessible, the following factors were chosen to obtain the multi-factor assessment system shown in Figure 1: loose solid matter reserves $S_{1}$, length ratio of sediment supply segment $S_{2}$, vegetation coverage $S_{3}$, watershed area $S_{4}$, main gully length $\mathcal{S}_{5}$, maximum relative elevation $S_{6}$, bending coefficient of main gully $S_{7}, 24 \mathrm{~h}$ maximum rainfall $S_{8}$, and annual average rainfall $S$. With reference to the studies in 
literature $[5,9]$, the assessment factor classification criteria were determined, as shown in Table 2.

\subsection{Determination of weights and comprehensive assessment values of factors}

Among the factors for assessment of debris flow risk degree, the primary and secondary factors have a principal-supplement relationship, which can be equally

Table 2. Classes and assigned values of debris flow risk factors.

\begin{tabular}{|c|c|c|c|c|c|c|}
\hline Class & 1 & 2 & 3 & 4 & 5 & 6 \\
\hline Assigned value & 0 & 0.2 & 0.4 & 0.6 & 0.8 & 1 \\
\hline$M /\left(10^{4} \mathrm{~m}^{3}\right)$ & $(0,1]$ & $(1,5]$ & $(5,10]$ & $(10,50]$ & $(50,100)$ & {$[100, \infty)$} \\
\hline$F / \%$ & $(0,5]$ & $(5,10]$ & $(10,20]$ & $(20,50]$ & $(50,100)$ & {$[100, \infty)$} \\
\hline$S_{1} /\left(10^{4} \mathrm{~m}^{3}\right)$ & $(0,100]$ & $(100,500]$ & $(500,1000]$ & $(1000,5000]$ & $(5000,10000)$ & {$[10000, \infty)$} \\
\hline$S_{2}$ & $(0,0.1]$ & $(0.1,0.2]$ & $(0.2,0.3]$ & $(0.3,0.4]$ & $(0.4,0.6)$ & {$[0.6, \infty)$} \\
\hline$S_{3} / \%$ & {$[60,100]$} & $(40,60)$ & $(30,40]$ & $(20,30]$ & $(10,20]$ & $(0,10]$ \\
\hline$S_{4} / \mathrm{km}^{2}$ & {$[50, \infty)$ or $(0.0,0.5]$} & $(0.5,2.0]$ & $(2.0,5.0]$ & $(5.0,10.0]$ & $(10.0,30.0]$ & $(30.0,50.0)$ \\
\hline$S_{5} / \mathrm{km}$ & $(0.0,0.5]$ & $(0.5,1.0]$ & $(1.0,2.0]$ & $(2.0,5.0]$ & $(5.0,10.0)$ & {$[10.0, \infty)$} \\
\hline$S_{6} / \mathrm{km}$ & $(0.0,0.2]$ & $(0.2,0.5]$ & $(0.5,0.7]$ & $(0.7,1.0]$ & $(1.0,1.5)$ & {$[1.5, \infty)$} \\
\hline$S_{7}$ & $(0.0,1.1]$ & $(1.1,1.2]$ & $(1.2,1.3]$ & $(1.3,1.4]$ & $(1.4,1.5)$ & {$[1.5, \infty)$} \\
\hline$S_{8} / \mathrm{mm}$ & $(0,25]$ & $(25,50]$ & $(50,75]$ & $(75,100]$ & $(100,150)$ & {$[150, \infty)$} \\
\hline$S_{9} / \mathrm{mm}$ & $(0,100]$ & $(100,200]$ & $(200,400]$ & $(400,600]$ & $(600,800)$ & {$[800, \infty)$} \\
\hline
\end{tabular}

weighted [4]. Therefore, the primary and secondary factors are respectively given a total weight of 0.5 . The two primary factors can be equally weighed [4-5], which means each factor is given a weight of 0.25 that is half of 0.5 .

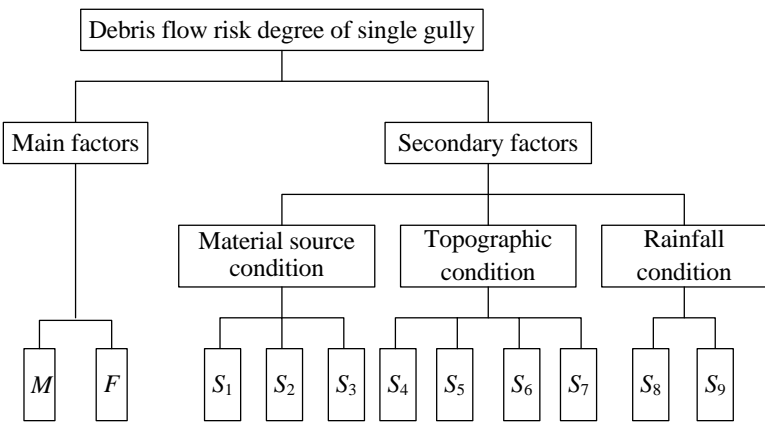

Figure 1. Assessment factor system of debris flow risk.

Secondary factors are weighted using the analytic hierarchy process [6]. In order to improve the reliability of subjective weighting, the group decision making method is used to determine the weights, which comprehensively considers the judgment results of several experts. Since it is difficult to reach a unanimous judgment result due to the difference in subjective preference and experience level of different experts, the key point in the study using the group decision making method is to unify the experts' views in group decision making [8]. In order to simply and effectively combine the judgment results of several experts, this paper adopts the data fusion algorithm to allocate the combination coefficient for each expert.
If $n$ experts weight $m$ secondary factors, the following weight matrix can be obtained:

$$
\mathbf{W}_{i}=\left(w_{i 1}, w_{i 2} \cdots, w_{i m}\right), i=1,2, \ldots, n
$$

Combination weighting of the weight matrix in Eq. (1) gives

$$
\mathbf{W}_{c}=\sum_{i=1}^{n} a_{i} \mathbf{W}_{i}
$$

where $\mathbf{W}_{c}$ is the combination weight matrix; $a_{i}$ is the combination coefficient; $\mathrm{W}_{i}$ is the weight matrix determined by the $i^{\text {th }}$ expert.

The combination coefficient is calculated using the concept of support [10] in the data fusion algorithm. This method takes the overall data as the reference object. Higher degree of support given by the overall data to the judgment result of an expert suggests higher reliability of this judgment result, and as a result, the corresponding judgment result should be given a larger combination coefficient.

Since there is more than one secondary factor, the concept of support involves the relationship between vectors. The support equation based on Euclidean distance [10] is used, which is defined as

$$
\begin{gathered}
r_{i j}=\exp \left(-\delta_{i j}\right) \\
\delta_{i j}=\sqrt{\sum_{k=1}^{m}\left(w_{i k}-w_{j k}\right)^{2}}
\end{gathered}
$$

where $r_{i j}$ is the support between different weight sequences; $\delta_{i j}$ is the Euclidean distance between different weight sequences.

Previously, the effect of the order of magnitude of data has not been taken into account during support computation. Apparently, lower order of magnitude leads to the fact that the support calculated by Eq. (3) 
is closer to 1 , and higher order of magnitude leads to the fact that the support calculated by Eq. (3) is closer to 0 . The calculated results of data with different orders of magnitude may vary greatly. Therefore, it is necessary to eliminate the effect of the order of magnitude, and calculation can be done by the following equation:

$$
\delta_{i j}^{\prime}=\delta_{i j} / \bar{w}_{i j}
$$

where $\bar{w}_{i j}$ is the mean value of all weights; $\delta_{i j}^{\prime}$ is the relative Euclidean distance after the effect of the order of magnitude is eliminated.

Therefore, the support can be redefined as

$$
r_{i j}=\exp \left(-\delta_{i j}^{\prime}\right)
$$

For combination weighting, a support matrix $\mathbf{M}$ is established as follows:

$$
\mathbf{M}=\left[\begin{array}{cccc}
r_{11} & r_{12} & \cdots & r_{1 n} \\
r_{21} & r_{22} & \cdots & r_{2 n} \\
\vdots & \vdots & \ddots & \vdots \\
r_{n 1} & r_{n 2} & \cdots & r_{n n}
\end{array}\right]
$$

Since the combination coefficient $a_{i}$ should combine the overall information of $r_{i 1}, r_{i 2}, \ldots, r_{i n}[10]$, a set of nonnegative numbers is required to give

$$
a_{i}=v_{1} r_{i 1}+v_{2} r_{i 2}+\cdots+v_{n} r_{i n}
$$

The matrix form is

$$
\mathbf{H}=\mathbf{M N}
$$

where $\mathbf{H}=\left[w, w_{2}, \ldots, w_{n}\right]^{\mathrm{T}}, \mathbf{N}=\left[v, v 2, \ldots, v_{n}\right]^{\mathrm{T}}$, and $\mathbf{M}$ is the nonnegative symmetric matrix; there exists the maximum modulus eigenvalue $\mu$. From $\mu \mathbf{N}=\mathbf{M N}$, the corresponding eigenvector can be obtained as $\mathbf{N}_{\mu}=\left[\mathrm{\nu}^{\mu}\right.$, $\left.V_{2}^{\mu}, \ldots, V_{n}^{\mu}\right]^{\mathrm{T}}$, and all data are nonnegative. According to the properties of eigenvectors and eigenvalues, the following equation can be used:

$$
a_{i}=v_{i}^{\mu} / \sum_{i=1}^{n} v_{i}^{\mu}
$$

$a_{i}$ is actually the comprehensive support given by the overall data to the judgment result of the $i^{\text {th }}$ expert, and the comprehensive weight can be determined by plugging it into Eq. (2).

Finally, the linear weighted sum method is used to calculate the comprehensive assessment value of debris flow risk degree by the equation below:

$$
R=0.25 M+0.25 F+\sum_{i=1}^{m} W_{c k} S_{k}
$$

The assessed level is determined according to the relationship between the risk level and the comprehensive assessment value of risk degree [11]: minor risk $(0 \sim 0.35)$, moderate risk $(0.35 \sim 0.60)$, high risk $(0.60 \sim 0.85)$, or extreme risk $\left(0.85^{\sim} 1\right)$.

\section{Risk assessment of typical debris flow gullies in the study area}

Due to limitation of survey data, only gullies with medium to large-scale debris flows are subject to risk assessment in this study. Table 3 shows the basic conditions of debris flows in these gullies. The types of debris flows listed in Table 3 are classified by watershed geomorphology and material source supply according to the Specification of geological investigation for debris flow stabilization (DZ/T 02202006).

When classified by watershed geomorphology, all medium to large-scale debris flows in the study area are gully-type debris flows. This type is represented by the Washiyan Gully; at the junction between the main and branch gullies, debris-flow fans are mostly retained except that hanging valleys are formed at the branch gully. Solid matter supply is mainly from loose materials on both banks of the gully and riverbed deposits.

When classified by material source supply mode, medium to large-scale debris flows in the study area include slope erosion-type, slag-type and compositetype debris flows. 1) There are two slope erosion-type debris flows. Main material sources for this type of debris flow include the abundant deluvium and eluvium on both sides of the gully and the loose deposits in channels; under the effect of rainfall, debris flows are formed due to erosion by surface runoff on slopes and channels. 2) There are three slag-type debris flows. This type is typical of man-made debris flows, and its main material sources are mining slags and tailings powder which, under the effect of rainfall, are washed away and form debris flows due to scouring and erosion by surface runoff. 3) There are three composite-type debris flows. Main material sources for this type include at least two of deposits in channels, slump deposits, slags and other materials, which are mixed under the effect of rainfall and form debris flows.

Table 3. Basic conditions of medium to large-scale debris flows in Luanchuan County.

\begin{tabular}{|c|c|c|c|}
\hline \multirow{2}{*}{ Location } & \multicolumn{2}{|c|}{ Type of debris flow } & \multirow{2}{*}{ Scale } \\
\cline { 2 - 3 } & $\begin{array}{c}\text { Classification } \\
\text { by watershed } \\
\text { geomorphology }\end{array}$ & $\begin{array}{c}\text { Classification } \\
\text { by material } \\
\text { source supply }\end{array}$ & \\
\hline $\begin{array}{c}\text { Shishu } \\
\text { Gully }\end{array}$ & Gully-type & $\begin{array}{c}\text { Slope erosion- } \\
\text { type }\end{array}$ & Large \\
\hline $\begin{array}{c}\text { Ganjiang } \\
\text { Gully }\end{array}$ & Gully-type & Slag-type & Large \\
\hline $\begin{array}{c}\text { Yudimiao } \\
\text { Gully }\end{array}$ & Gully-type & Slag-type & Medium \\
\hline $\begin{array}{c}\text { Zhazi } \\
\text { Gully }\end{array}$ & Gully-type & $\begin{array}{c}\text { Composite- } \\
\text { type }\end{array}$ & Medium \\
\hline $\begin{array}{c}\text { Tuluanpa } \\
\text { Gully }\end{array}$ & Gully-type & $\begin{array}{c}\text { Slope erosion- } \\
\text { type }\end{array}$ & Large \\
\hline Yinhe & Gully-type & Slag-type & Medium \\
\hline
\end{tabular}




\begin{tabular}{|c|c|c|c|}
\hline Gully & & & \\
\hline $\begin{array}{c}\text { Nanwa } \\
\text { Gully }\end{array}$ & Gully-type & $\begin{array}{c}\text { Composite- } \\
\text { type }\end{array}$ & Medium \\
\hline $\begin{array}{c}\text { Washiyan } \\
\text { Gully }\end{array}$ & Gully-type & $\begin{array}{c}\text { Composite- } \\
\text { type }\end{array}$ & Large \\
\hline
\end{tabular}

Table 4 lists the basic data of each debris flow gully. Among them, the $24 \mathrm{~h}$ maximum rainfall and the annual average rainfall are from statistical data provided by the Meteorological Station of Luanchuan County. The annual average rainfall is the mean value during 1957 2011. Since there are few records about historical breakouts of debris flows in each gully, the frequency of regional group occurrence is chosen as the frequency of debris flow occurrence during assessment of debris flow risk. The average frequency is once every 10.5 years, i.e., $9.5 \%$.

First of all, the weight of each secondary factor is determined. Based on the scores given by four experts, the weight of secondary factors, which totals 0.5 , is allocated step by step to the last level using the analytic hierarchy process.

The support is calculated by Eqs. (4) (6), and a support matrix $\mathbf{M}$ is established as follows:

$$
\mathbf{M}=\left[\begin{array}{llll}
1.000 & 0.572 & 0.205 & 0.157 \\
0.572 & 1.000 & 0.311 & 0.184 \\
0.205 & 0.311 & 1.000 & 0.182 \\
0.157 & 0.184 & 0.182 & 1.000
\end{array}\right]
$$

It is obvious that the support for the judgment result of each expert relative to itself is maximum (1.00). Besides, the support between the judgment results of experts 1 and 2 is the second largest (0.572). This suggests the two judgment results are relatively close to each other. The supports between the judgment results of expert 4 and the other three experts are relatively small $(0.157,0.184,0.182)$, and therefore it will be inevitably given a relatively small combination coefficient.

The

Table 4. Basic data of each debris flow gully

\begin{tabular}{|c|c|c|c|c|c|c|c|c|}
\hline $\begin{array}{c}\text { Debris flow } \\
\text { gully }\end{array}$ & $\begin{array}{c}\text { Shishu } \\
\text { Gully }\end{array}$ & $\begin{array}{c}\text { Ganjiang } \\
\text { Gully }\end{array}$ & $\begin{array}{c}\text { Yudimiao } \\
\text { Gully }\end{array}$ & $\begin{array}{c}\text { Zhazi } \\
\text { Gully }\end{array}$ & $\begin{array}{c}\text { Tuluanpa } \\
\text { Gully }\end{array}$ & $\begin{array}{c}\text { Yinhe } \\
\text { Gully }\end{array}$ & $\begin{array}{c}\text { Nanwa } \\
\text { Gully }\end{array}$ & $\begin{array}{c}\text { Washiyan } \\
\text { Gully }\end{array}$ \\
\hline$M /\left(10^{4} \mathrm{~m}^{3}\right)$ & 10 & 73 & 1 & 5 & 17 & 6 & 2 & 20 \\
\hline$F / \%$ & 9.5 & 9.5 & 9.5 & 9.5 & 9.5 & 9.5 & 9.5 & 9.5 \\
\hline$S_{1} /\left(10^{4} \mathrm{~m}^{3}\right)$ & 40 & 181 & 5 & 8 & 62 & 23 & 1 & 75 \\
\hline$S_{2}$ & 0.15 & 0.31 & 0.15 & 0.11 & 0.12 & 0.22 & 0.24 & 0.05 \\
\hline$S_{3} / \%$ & 85 & 55 & 85 & 85 & 85 & 90 & 80 & 80 \\
\hline$S_{4} / \mathrm{km}^{2}$ & 1.17 & 6.52 & 0.43 & 1.65 & 12.28 & 3.71 & 0.07 & 9.43 \\
\hline$S_{5} / \mathrm{km}$ & 2.1 & 2.7 & 1.9 & 2.9 & 4.8 & 1.5 & 0.3 & 7.5 \\
\hline$S_{6} / \mathrm{km}$ & 0.44 & 0.70 & 0.29 & 0.31 & 0.24 & 0.41 & 0.14 & 0.50 \\
\hline$S_{7}$ & 1.10 & 1.76 & 1.09 & 1.05 & 1.26 & 1.16 & 1.01 & 1.39 \\
\hline$S_{8} / \mathrm{mm}$ & 158.5 & 158.5 & 158.5 & 158.5 & 158.5 & 158.5 & 158.5 & 158.5 \\
\hline$S_{9} / \mathrm{mm}$ & 854.6 & 854.6 & 854.6 & 854.6 & 854.6 & 854.6 & 854.6 & 854.6 \\
\hline
\end{tabular}

comprehensive support given by the overall data to the judgment result of each expert is calculated by Eqs. (9) and (10), i.e., the combination coefficient $\mathbf{a}=(0.295$, 0.315, 0.221, 0.169). According to Eq. (2), the combination weight is calculated as $\mathrm{W}_{\mathrm{c}}=(0.137,0.029$, $0.022,0.018,0.016,0.051,0.019,0.118,0.091)$.

According to the classes of debris flow risk factors in Table 2, values are assigned to the basic data of each debris flow gully listed in Table 4, and the debris flow risk degree is calculated according to Eq. (11). For contrastive analysis, the model in literature [5] is also used to calculate the debris flow risk degree. This model determines the weight of each factor by the objective weighting method, without taking the rainfall condition into account. Table 5 shows the final results of debris flow risk degree in each gully. As can be seen from Table 5, due to the difference in assessment factors and weights of factors, the two models provide different assessment results. The model used in literature [5] gives lower assessment values and levels; except that Ganjiang Gully faces moderate risk, all debris flow gullies exhibit minor risk. Assessment values obtained by the model proposed in this paper are significantly higher than those obtained by the model in literature [5]. This is because the former additionally take into account the rainfall condition while there is abundant rainfall in Luanchuan County which contributes to the occurrence of debris flow. Let's take Shishu Gully, an old debris flow gully, as an example. The latest debris flow occurred in 2010, which was a large-scale debris flow. During the outbreak of the debris flow, downstream cultivated land was completely washed away, sweeping down and forming nearly 300m of deposits in the channel; 12 resident houses were destroyed. Under the effect of heavy rainfall, it is still 
possible that debris flows break out, and it is more in line with the actual situation to judge that the gully faces moderate risk.

On the whole, all debris flow gullies face minor to moderate risks. Among them, Ganjiang Gully, a slagtype debris flow gully, exhibits the highest risk degree. On July 24, 2010, a debris flow occurred as a result of tailings dam break. Therefore, its tailings dam should be checked and reinforced in time to avoid reoccurrence of debris flows.

Table 5. Results of debris flow risk degree and risk level assessment

\begin{tabular}{|c|c|c|c|c|}
\hline \multirow{2}{*}{$\begin{array}{c}\text { Debris flow } \\
\text { gully }\end{array}$} & \multicolumn{2}{|c|}{$\begin{array}{c}\text { Group decision } \\
\text { making model }\end{array}$} & \multicolumn{2}{c|}{ Model in literature } \\
\cline { 2 - 5 } & $\begin{array}{c}\text { Risk } \\
\text { degree }\end{array}$ & Risk level & $\begin{array}{c}\text { Risk } \\
\text { degree }\end{array}$ & $\begin{array}{c}\text { Risk } \\
\text { level }\end{array}$ \\
\hline Shishu Gully & 0.39 & Moderate & 0.21 & Minor \\
\hline $\begin{array}{c}\text { Ganjiang } \\
\text { Gully }\end{array}$ & 0.57 & Moderate & 0.41 & Moderate \\
\hline $\begin{array}{c}\text { Yudimiao } \\
\text { Gully }\end{array}$ & 0.28 & Minor & 0.15 & Minor \\
\hline $\begin{array}{c}\text { Zhazi Gully } \\
\text { Tuluanpa } \\
\text { Gully }\end{array}$ & 0.34 & Minor & 0.18 & Minor \\
\hline Yinhe Gully & 0.40 & Moderate & 0.25 & Minor \\
\hline Nanwa Gully & 0.32 & Minor & 0.11 & Minor \\
\hline $\begin{array}{c}\text { Washiyan } \\
\text { Gully }\end{array}$ & 0.45 & Moderate & 0.25 & Minor \\
\hline
\end{tabular}

The assessed debris flow risk levels of all gullies are relatively low, the reasons for which are summarized as follows:

(1) Debris flows do not break out frequently in Luanchuan County, which can occur easily only under the effect of heavy rainfall.

(2) Loose solid matters in each debris flow gully were significantly reduced during the debris flows taking place on July 24, 2010, and most of them were washed out of the gully, reducing the risk of reoccurrence of debris flows.

(3) Some gullies are characterized by small watershed area, low maximum elevation, small bending coefficient of main gully bed and high vegetation coverage, which explain why the debris flow risk degrees in these gullies are relatively low.

\section{Conclusion}

In the multi-factor comprehensive assessment methods for debris flow risk, it is really important to determine the weight of each assessment factor since this affects the reliability of the assessment results. At present, common methods for weight determination include subjective, objective and combination weighting methods. The objective weighting method is often dependent on the fluctuation of data, and the weight obtained by this method can be affected by sample data. The subjective weighting method can, to some extent, reflect the relationship between the debris flow risk and the factor, but is dependent on the expert's subjective will and experience level. Although the combination of these two methods can reconcile the difference between them to some extent, the significance of combination weight is no longer clear. Therefore, the group decision making method is suggested in this paper. The weights determined by this method not only can accurately reflect the importance of each factor, but also can improve the reliability of subjective weighting. Group decision making is realized using the analytic hierarchy process and the data fusion algorithm. In this method, the expert combination weight is determined; on this basis, a model for comprehensive assessment of debris flow risk degree is established by the linear weighted sum method, and risk assessment is performed for gullies with medium to large-scale debris flows in the study area. The assessment results show that all debris flow gullies face minor to moderate risks. For gullies with high risk level, it is suggested to timely clear material sources in channels and construct or reinforce retaining dams in order to prevent re-occurrence of debris flows.

\section{ACKNOWLEDGEMENTS}

This work was supported by the CRSRI Open Research Program (grant number CKWV2016391/KY), the Research Project of Education Department of Sichuan Province (grant number 17ZB0222) and Research Project of Key Research Base of Humanities and Social Sciences of Sichuan Province -- Research Center of Prediction, Early Warning and Emergency Management of Meteorological Disaster (ZHYJ16YB05).

\section{References}

1. L.F. Shao, Z.W. Peng, H.M. Yu, P.Y. Chen, S.N. Wang, Y.Y. Hu, J. Nat. Disa. 22, 131-141 (2013)

2. L.F. Shao, Electron. J. Geotech. Eng. 19, 8761-8772 (2014)

3. X.L. Liu, J. Nat. Disa. 11, 1-8 (2002)

4. P.Y. Chen, H.M. Yu, Y. Liu, C. Li, Z.W. Peng, Rock Soil Mech. 34, 449-454 (2013)

5. P.Y. Chen, J.S. Qiao, Z.W. Peng, K. Xie, H.M. Yu, Rock Soil Mech. 34, 1409-1415 (2013) 
6. H.S. Dang, C. Xie, L. Wang, Math. Pract. Theory 45, 176-183 (2015)

7. X.Z. Wang, C.Z. Sun, J. Liaoning Normal Univ. (Nat. Sci. Ed.) 39, 553-560 (2016)

8. Y.Y. Wu, Z.S. Hua, Y. Zha, Oper. Res. Manag. Sci. 12, 16-21 (2003)

9. H. Liu, H. Chen, Resour. Environ. Yangtze Basin 21, 1032-1038 (2012)

10. P.Y. Chen, H.M. Yu, H.P. Shi, Mod. Tunn. Tech. 53, 38-44 (2016)

11. X.L. Liu, C. Tang, Risk assessment of debris flow (Science Press, Beijing, 1995) 